\title{
PREFACE
}

\section{Ulcerative Colitis}

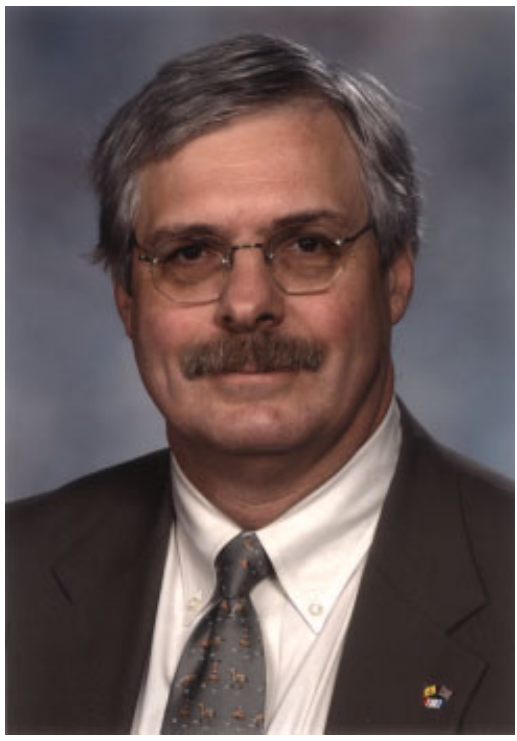

This issue of Clinics in Colon and Rectal Surgery deals with ulcerative colitis. For over 20 years, total proctocolectomy and the ileoanal anastomosis has been the mainstay of surgical treatment for this devastating disease. We have carefully chosen various aspects of ulcerative colitis on which to report. Some of these, because they are in the shadow of the ileoanal procedure, are rarely discussed but are still very viable alternatives for many patients.

Medical treatment of ulcerative colitis continues to evolve with recent refinements and is ably discussed by Dr. Uma Mahadevan, a gastroenterologist at the University of California, San Francisco.

Ulcerative proctitis is less often discussed in current times as a separate entity of ulcerative colitis. Dr. Charles Whitlow of the Ochsner Clinic in New Orleans defines this interesting and challenging entity for us, including prognosis and appropriate treatment.

Various aspects of the surgical management of ulcerative colitis are also presented, including the ileorectal anastomosis and the fate of the retained rectum, which is still a fairly common and appropriate operation for patients with very mild colitis in the rectum. This operation is increasingly performed in patients with obesity, in whom an ileal pouch-anal procedure may not be feasible. Dr. Adam Juviler and Dr. Neil Hyman at the University of Vermont College of Medicine present this very viable option.

The technical aspects of ileal pouch surgery, including single-stage procedures, double-stapled procedures, hand-sewn anastomosis, and various types of pouches, are the topics of Dr. Peter Carne of Melbourne, Australia and Dr. John Pemberton of the Mayo Clinic Foundation. Dr. Feza Remzi and Dr. Emre Gorgun discuss the complications of ileoanal pouches and their management, drawing on their wealth of experience with revisional pouch surgery at the Cleveland Clinic.

Continent ileostomy for chronic ulcerative colitis has become a much less frequent operation in the last 2 decades, but there is a small and select group for whom this is the perfect procedure. Dr. David Beck discusses the place of this procedure today along with the technique of $\mathrm{T}$-pouch construction, which has recently been developed.

It seems that severe ulcerative colitis has been diagnosed with increasing frequency in the elderly population, and often this colitis is refractory to medical management. Dr. Eric Dozois of the Mayo Clinic Foundation discusses this operation which is perhaps the second-most-often performed operation for ulcerative colitis at present.

Dr. Tracey Arnell of the New York Presbyterian Hospital-Columbia Campus rounds out this issue with current thinking on the surgical management of acute colitis and toxic megacolon, discussing the particularly important issues of how long to wait with aggressive medical management before taking patients to surgery and what operations should be considered in the emergency situation.

It has been an honor and a pleasure for me to be Guest Editor of this issue, and in particular to read this collection of articles written by some of the best minds and clinical practitioners in the treatment of this complicated disease.

Bruce G. Wolff, M.D. Guest Editor ${ }^{1}$

Ulcerative Colitis; Editor in Chief, David E. Beck, M.D.; Guest Editor, Bruce G. Wolff, M.D. Clinics in Colon and Rectal Surgery, volume 17, number 1, 2004. Address for correspondence and reprint requests: Bruce G. Wolff, M.D., Division of Colon and Rectal Surgery, Mayo Clinic Foundation, 200 First Street SW, Rochester, MN 55905, E-mail: wolff.bruce@mayo.edu. ${ }^{1}$ Division of Colon and Rectal Surgery, Mayo Clinic Foundation, Rochester, Minnesota. Copyright (C) 2004 by Thieme Medical Publishers, Inc., 333 Seventh Avenue, New York, NY 10001, USA. Tel: +1(212) 584-4662. 1531-0043,p;2004,17,01,003,003,ftx,en;ccrs00154x. 